\title{
Using distinct molecular signatures of human monocytes and dendritic cells to predict adjuvant activity and pyrogenicity of TLR agonists
}

\author{
Richard Kenmoe Kamgang - Inês Ramos • Lurdes Rodrigues Duarte • \\ Mascia Ghielmetti · Marina Freudenberg • Clemens Dahinden · \\ Elisabetta Padovan
}

Received: 10 December 2007 / Published online: 19 February 2008

(C) Springer-Verlag 2008

\begin{abstract}
We present a systematic study that defines molecular profiles of adjuvanticity and pyrogenicity induced by agonists of human Toll-like receptor molecules in vitro. Using $\mathrm{P}_{3} \mathrm{CSK}_{4}$, Lipid A and Poly I:C as model adjuvants we show that all three molecules enhance the expansion of IFN $\gamma^{+} / \mathrm{CD}^{+} \mathrm{T}$ cells from their naïve precursors following priming with allogeneic DC in vitro. In contrast, co-culture of naive $\mathrm{CD} 4^{+} \mathrm{T}$ cells with allogeneic monocytes and TLR2/TLR4 agonists only resulted in enhanced T cell proliferation. Distinct APC molecular signatures in response to each TLR agonist underline the dual effect observed on $\mathrm{T}$ cell responses. Using protein and gene expression assays, we show that TNF- $\alpha$ and CXCL10 represent DC-restricted molecular signatures of TLR2/TLR4 and TLR3 activation, respectively, in sharp contrast to IL-6 produced by monocytes upon stimulation with $\mathrm{P}_{3} \mathrm{CSK}_{4}$ and Lipid A. Furthermore, although all TLR agonists are able to up-regulate proIL-1 $\beta$ specific gene in both cell types, only monocyte activation with Lipid A results in detectable IL-1 $\beta$ release. These molecular profiles, provide a simple
\end{abstract}

E. Padovan

Lisbon Medical School, 1649-028 Lisbon, Portugal

I. Ramos $\cdot$ L. Rodrigues Duarte $\cdot$ E. Padovan $(\square)$

Instituto Gulbenkian de Ciência, Lymphocyte Activation,

Rua da Quinta Grande 6, 2780-156 Oeiras, Portugal

e-mail: epadovan@igc.gulbenkian.pt

R. K. Kamgang · M. Ghielmetti

University of Bern, 3010 Bern, Switzerland

M. Freudenberg

Max Planck Institute for Immunobiology, 79108 Freiburg,

Germany

C. Dahinden

Bern Institute of Immunology, 3010 Bern, Switzerland screen to select new immune enhancers of human Th1 responses suitable for clinical application.

Keywords Adjuvant screening · Human · Dendritic cell · Monocytes $\cdot$ Th1 cells
Abbreviations
CB Cord blood
CT Cholerae toxin
DC Dendritic cells
IPSE IL-4-inducing principle of SME
Mo Monocytes
Osp A Outer surface lipoprotein A
PI Propidium iodide
PT Pertussis toxin
SME Schistosoma mansoni eggs

\section{Introduction}

Toll-like receptors are a family of pathogen recognition receptors, constitutively expressed on mononuclear phagocytes [1]. Up to 13 TLR molecules have been described in mammals, and for most of them a cognate natural ligand has been identified [2]. Thus, TLR2 senses bacterial lipopeptides [3], TLR3 recognizes viral particles [4] and TLR4 binds LPS from gram-negative bacteria [5].

Engagement of TLR on professional APC is required for the development of protective T cell responses in vivo [6]. Indeed, instruction of APC through TLR upon natural infection or administration of live or attenuated vaccines elicits long-term immunity, while exposure of antigen formulations that lack the capacity to signal through the TLR system are poorly immunogenic [7]. These observations have generated a strong demand for the rational design of 
synthetic immune enhancers able to complement the activity of subunit vaccines. Given the instructive role of TLR signaling in the development of adaptive immunity, various synthetic analogs of TLRs have been identified and considered for clinical application [8]. As new compounds become available, there is need to develop applicable screening methods predicting adjuvanticity and safety of those molecules [9].

We present here a systematic in vitro study, which defines a correlation between molecular profiles induced by TLR agonists and their adjuvant activity. We studied three putative adjuvants: the synthetic bacterial lipopeptide ana$\log \mathrm{P}_{3} \mathrm{CSK}_{4}$, Lipid A from $S$. minnesota LPS and the synthetic analog of dsRNA, Poly I:C, each interacting with a different TLR complex. Since the expression pattern of TLR molecules is compartmentalized among functionally different subpopulations of APC [10-12], we compared the activation program induced by those TLR2, TLR4 and TLR3 agonists in DC and Mo, that are considered models of "professional" versus "non-professional" APC, respectively [13].

Our aim is to define cell-restricted molecular signatures induced upon TLR instruction in APC that correlate with the capacity of specific receptor agonists to act as safe immune enhancers for human Th1 responses.

\section{Materials and methods}

Chemicals and media

The synthetic bacterial lipopeptide analogs and the $\mathrm{CSK}_{4}$ peptide were produced as endotoxin-free compounds by EMC microcollections (Tübingen, D), dissolved in PBS and solubilized by sonication prior to use. Poly I:C was from Sigma (Buchs, CH). Lipid A from S. minnesota LPS, SME and IPSE were prepared as described elsewhere [14, 15]. Lip-OspA and MDP-OspA were kindly provided by M. Simons (Max Planck Institute for Immunebiology, Freiburg, D). PT and CT were from Calbiochem (San Diego, CA, USA). CFSE (5(and6)carboxyfluorescein diacetate succinimidyl ester) was provided by Molecular Probes (Eugene, OR, USA). Complete RPMI 1640 contained 1\% sodium pyruvate, non-essential amino acids, glutamax and kanamycin and $0.1 \% \beta$ mercaptoethanol (Invitrogen, Barcelona, E). For cell culture, either 5\% human AB serum (RPMI-HS; SRK, Bern, CH) or $10 \%$ heat inactivated FCS (RPMI-FCS; Invitrogen, Barcelona, E) was added.

\section{Mo and DC cultures}

Blood specimens from healthy donors were kindly provided by SRK (Bern, Switzerland), Dr. J. Esteves (Hospital
Egaz Moniz, Lisbon, P) and Dr. T. Ghielmetti (University Hospital, Bern, CH) upon donor's informed consent. PBMC were separated by Histopaque 1077 gradient centrifugation and $\mathrm{CD} 14^{+}$Mo isolated by positive sorting using anti-CD14-conjugated microbeads (Miltenyi Biotech, Bergisch Gladbach, D). Mo-derived DC were generated from $\mathrm{CD} 14^{+}$Mo upon culture in RPMI-FCS medium supplemented with $50 \mathrm{ng} / \mathrm{ml}$ GM-CSF and $100 \mathrm{ng} / \mathrm{ml} \mathrm{IL-4}$ (RnD systems, Abingdon, UK) for 5 days. For activation, cells where stimulated with $100 \mathrm{ng} / \mathrm{ml}$ of $\mathrm{P}_{3} \mathrm{CSK}_{4}$ or equimolar $(69 \mathrm{nM})$ concentrations of $\mathrm{CSK}_{4}$ peptide or any other lipopeptide analog, $100 \mathrm{ng} / \mathrm{ml}$ of Poly I:C or Lipid A, if not otherwise specified. Lip-OspA, MDP-OspA CT, PT, SMEA, IPSE were used at $1 \mu \mathrm{g} / \mathrm{ml}$. Release of cytokines and chemokines in culture supernatants and cell phenotypes were assessed after $16 \mathrm{~h}$ of stimulation by specific ELISA assays and FACS analysis. Gene expression was measured after $5 \mathrm{~h}$ of activation by qRT-PCR.

\section{ELISA assays}

Cytokines and chemokines released in cell culture supernatants were determined by quantitative ELISA assays. Specific antibody pairs and standards for TNF- $\alpha$, IL-6, CCL2, and CXCL10 were from BD PharMingen (San Diego, CA, USA), those specific for IL- $1 \beta$ were provided by RnD Systems (Abingdon, UK). Samples were read in a Spectramax190 plate reader and analyzed using SOFTmax software (Bucher biotech AG, Basel, $\mathrm{CH}$ ). Data are presented as mean results from different donors \pm SD. Student's $t$ test was used to compare pared samples.

\section{FACS analysis}

Cell phenotype was evaluated by cell surface staining. FITC-conjugated mouse antibodies to human CD14, CD1a (BD Pharmingen, San Diego, CA, USA) and TLR2 (eBioscience, San Diego, CA, USA) or isotype controls antibodies, were added to the cell pellet and incubated for $30 \mathrm{~min}$ at $4^{\circ} \mathrm{C}$. Samples were then washed, diluted in PBS containing PI to label dead cells, and analyzed on a FACSCalibur (BD Biosciences, San Jose, CA, USA) using CellQuestPro (BD Biosciences, San Jose, CA, USA) software. $\mathrm{PI}^{+}$cells never exceeded $10 \%$ of the total population.

\section{Quantitative gene expression assays}

Total cellular mRNA was isolated using RNAeasy kit (Qiagen, Valencia, CA, USA) following manufacturer's instruction. Purified mRNA was reverse transcribed into cDNA using the TaqMan reverse transcription reagents from Applied Biosystem (Foster City, CA, USA). Expression 
of selected genes was determined by qRT-PCR with specific primers and probes provided by Applied Biosystem (Foster City, CA, USA), according to provider's guidelines. The following assays-on-demand were used: CCL3/ Hs00234142_m1; CCL5/Hs00174575_m1; CCL20/Hs00 171125_m1; CCL22/Hs00171080_m1; CX3CL1/Hs00171 086_m1; CXCL10/Hs00171042_m1; EBI3/Hs_0019495 7_m1; IL27p28/Hs00377366_m1; IFNB1/Hs00277188_s1; IFNG/Hs00174143_m1; IL1B/Hs00174097_m1; IL4/Hs00 174122_m1; IL7/Hs00174202_m1; IL10/Hs00174086_m1; IL12A/Hs00168405_m1; IL12B/Hs00233688_m1; IL15/ Hs00542571_m1; IL18/Hs00155517_m1; IL23/0037232 4_m1; TGFB1/Hs00171257_m1; TNF $\alpha / H s 00174128 \_m 1 ;$ TLR1/00413978_m1; TLR2/Hs00610101_m1; TLR3/Hs00 152933_m1; TLR4/Hs00152939_m1; TLR6/00271977_s1. Samples were analyzed using ABI Prism 7700 or $7900 \mathrm{HT}$ Sequence Detection Systems. Average Cycle threshold (Ct) numbers of triplicate assays were derived from the exponential phase of PCR amplification. For each gene a $\Delta \mathrm{Ct}$ value was calculated by subtracting the $\mathrm{Ct}$ obtained for the reference $18 \mathrm{~S}$ gene. The fold increase in genes expression was calculated as Relative Quantity (R. Q.) of gene " $x$ " in the cell population A as compared to a calibrator cell population $\mathrm{B}$ derived by $2^{\Delta \Delta \mathrm{Ctx}}$ where $\Delta \Delta \mathrm{Ctx}=\Delta \mathrm{CtxA} \Delta \mathrm{CtxB}$.

$\mathrm{T}$ cell activation assays

CB samples were collected after vaginal birth in heparinized tubes, upon donors' formal consent. To assess $\mathrm{T}$ cells proliferation, purified CB-PBMC were labeled with $1.0 \mu \mathrm{M}$ CFSE for $8 \mathrm{~min}$ at $37^{\circ} \mathrm{C}$, extensively washed, diluted in RPMI-HS medium and cultured at $4 \times 10^{5}$ per ml with $\mathrm{CSK}_{4}, \mathrm{P}_{3} \mathrm{CSK}_{4}$, Lipid A or Poly I:C in the presence or absence of allogeneic DC $\left(10^{5} / \mathrm{ml}\right)$ or CD14 $4^{+}$Mos $\left(10^{5}-\right.$ $4 \times 10^{5}$ per $\mathrm{ml}$ ), prepared from the same donor. After 6 days, cells were stained with PE-conjugated anti-CD3 and APC-conjugated anti-CD4 antibodies, diluted in PBS containing PI, and analyzed on a FACSCalibur. Proliferative responses were quantified by measuring the loss of CFSE staining on gated $\mathrm{CD}^{+} / \mathrm{CD}^{+}$lymphocytes. To assess $\mathrm{T}$ cell differentiation, co-cultures were set using unlabeled CB-PBMC. After 6 days cells were stimulated for $8 \mathrm{~h}$ with $50 \mathrm{ng} / \mathrm{ml}$ PMA and $0.5 \mu \mathrm{g} / \mathrm{ml}$ Ionomycin (Sigma, Buchs, CH), adding Brefeldin A at $10 \mu \mathrm{g} / \mathrm{ml}$ for the least $4 \mathrm{~h}$. Cells were then collected and surface stained with PerCP-conjugated anti-CD3 and APC-conjugated anti-CD4 mAbs (BD PharMingen, San Diego, CA, USA). After washing, cells were fixed in $2 \%$ Paraformaldehyde and permeabilized with $1 \%$ Saponin (Sigma, Buchs, $\mathrm{CH}$ ). Intracellular cytokines were finally detected by staining with PE-conjugated anti-IL4 and FITC-conjugated antiIFN $\gamma$ mAbs (BD PharMingen, San Diego, CA, USA) in the presence of mouse $\mathrm{IgG}$ at $300 \mu \mathrm{g} / \mathrm{ml}$ (Jakson Laboratories, Bar Harbor, ME, USA). After final washing samples were analyzed on a FACSCalibur by acquiring a total of $2 \times 10^{4}$ gated $\mathrm{CD}^{+} / \mathrm{CD}^{+}$lymphocytes.

\section{Results}

Effect of $\mathrm{P}_{3} \mathrm{CSK}_{4}$, Lipid A and Poly I:C on T cell activation

We first selected three different molecules known to act as specific TLR ligands: the synthetic bacterial lipopeptide analog $\mathrm{P}_{3} \mathrm{CSK}_{4}$ which is an agonist for TLR2/TLR1 heterodimers, Lipid A from S. minnesota LPS that binds to TLR4, and Poly I:C which depends on TLR3 for cell activation [35]. In addition, we used the biologically inactive $\mathrm{CSK}_{4}$ derivative, as negative control of stimulation $[16,17]$.

We then compared the effect of these three molecules on naive $\mathrm{T}$ cell activation in vitro. To this aim, we first cultured CFSE-labeled CB-PBMC with $\mathrm{CD}_{14}{ }^{+}$Mo or DC both prepared from the peripheral blood of the same allogeneic adult individual, in the presence or absence of TLR agonist, and assessed $\mathrm{T}$ cell proliferation by the loss of CFSE dye in proliferating $\mathrm{CD}^{+} / \mathrm{CD}^{+}$lymphocytes. In cultures devoid of allogeneic APC, $\leq 9.10 \%$ of T cells were CFSE $^{\mathrm{dim}}$ and represented the level of non-specific proliferation in vitro; similar results were obtained with Mo co-cultures in the presence of $\mathrm{CSK}_{4}$ and Poly I:C (Fig. 1a). In contrast, stimulation of Mo co-cultures with $\mathrm{P}_{3} \mathrm{CSK}_{4}$ and Lipid A resulted in up to sevenfold increase in T cell proliferation (Fig. 1a). Allogeneic DC consistently induced T cell proliferation in the presence of $\mathrm{CSK}_{4}$, and all TLR agonists enhanced this effect (Fig. 1a).

We next examined the differentiation of naive lymphocytes to effector Th1 or Th2 cells, by assessing the expansion of IFN- $\gamma$ versus IL-4 producing T cells, in CB-PBMC/ APC co-cultures with or without TLR agonist [18]. In the absence of APC, cytokine-producing cells represented $\leq 0.95 \%$ of the total $\mathrm{CD}^{+} / \mathrm{CD}^{+} \mathrm{T}$ lymphocytes, irrespective of the TLR agonist used for stimulation (Fig. 1b, top panels). Upon co-culture with allogeneic $\mathrm{CD} 14^{+} \mathrm{Mo}$ and TLR agonist the frequency of cytokine-producing $\mathrm{T}$ cells was $\leq 1.99 \%$ (Fig. 1b, central panels). In contrast, in cultures stimulated with allogeneic DC, all three TLR agonists promoted a consistent expansion of IFN $-\gamma$ producing $\mathrm{T}$ lymphocytes over IL-4 secreting cells (Fig. 1b, lower panels). In $\mathrm{P}_{3} \mathrm{CSK}_{4}$-conditioned cultures, up to $18.9 \%$ of the $\mathrm{CD}^{+} / \mathrm{CD}^{+}{ }^{+} \mathrm{T}$ cells produced IFN- $\gamma$, compared to 7.71 and 6.04\% upon Lipid A and Poly I:C stimulation, respectively (Fig. 1b, lower panels). Mean results of independent experiments failed to demonstrate $\mathrm{T}$ cell differentiation in $\mathrm{CB}$ PBMC/APC co-cultures with $\mathrm{CSK}_{4}$ control peptide, irrespective of the type of APC used for stimulation (Fig. 1c). 

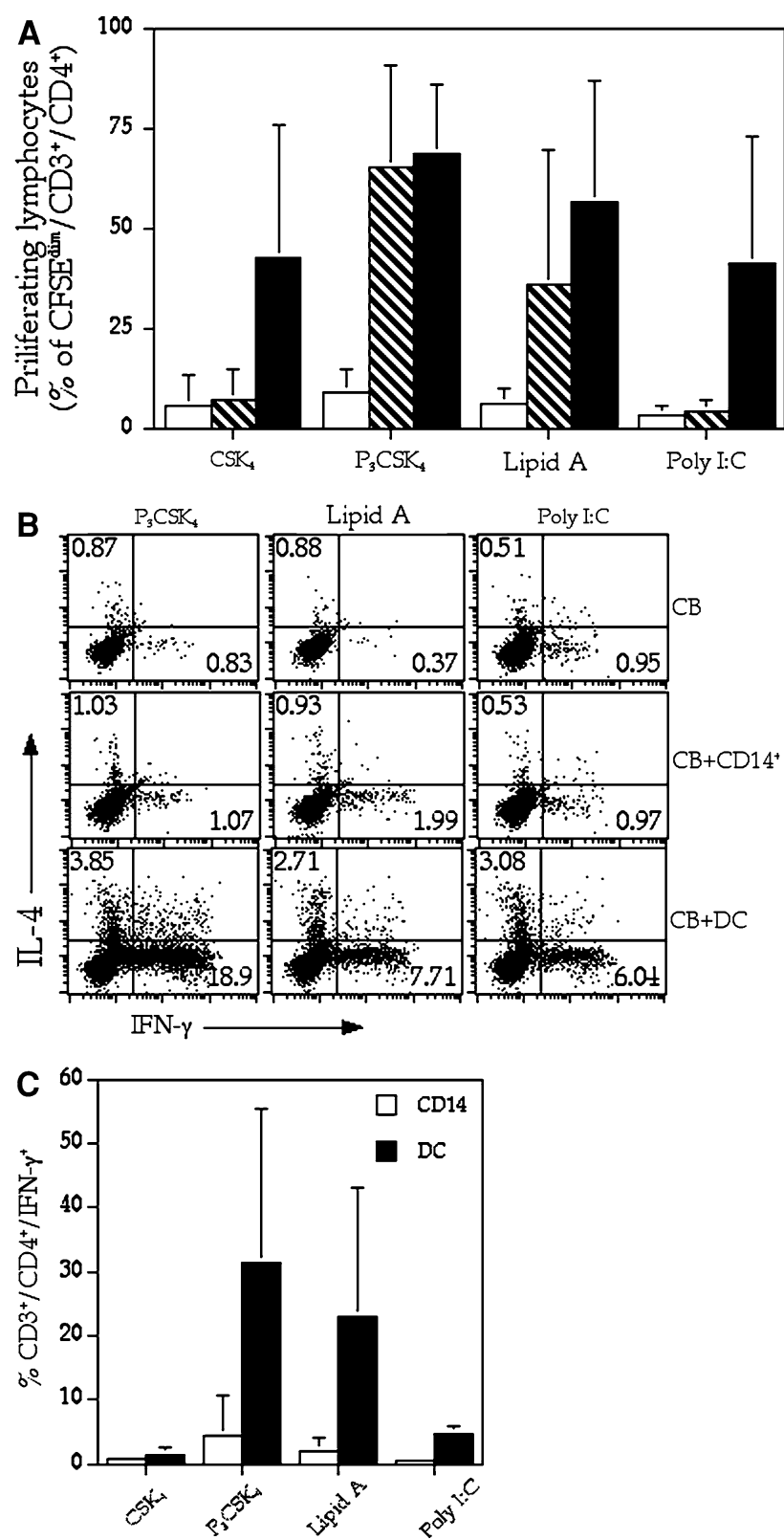

Fig. 1 Effect of TLR2, TLR4 and TLR3 agonists on naive T cell activation. a CFSE-labeled CB-PBMC were cultured alone (white bars), or stimulated with allogeneic $\mathrm{CD} 14^{+} \mathrm{Mo}$ (hatched bars) or Mo-derived DC (black bars), in the presence of $\mathrm{CSK}_{4}, \mathrm{P}_{3} \mathrm{CSK}_{4}$, Lipid A, or Poly $\mathrm{I}: \mathrm{C}$, as indicated in the bottom line. $\mathrm{T}$ cell proliferation was assessed by measuring the frequency of $\mathrm{CFSE}^{\mathrm{dim}} / \mathrm{CD}^{+} / \mathrm{CD}^{+}$lymphocytes by FACS analysis. b Unlabeled CB-PBMC were stimulated as in a and assed for $\mathrm{T}$ cell differentiation by detection of intracellular IL-4 versus IFN- $\gamma$ on gated $\mathrm{CD}^{+} / \mathrm{CD}^{+}$lymphocytes; numbers indicate the percentage of cytokine-producing $\mathrm{T}$ cells. c Frequency of $\mathrm{CD}^{+} / \mathrm{CD}^{+} /$ IFN- $\gamma^{+}$cells upon priming with allogeneic $\mathrm{CD} 14^{+}$Mo (white bars) or DC (black bars) in the presence of $\mathrm{CSK}_{4}, \mathrm{P}_{3} \mathrm{CSK}_{4}$, Lipid A or Poly I:C. Data represent mean results \pm SD obtained from four independent experiments

The capacity of each TLR agonist to enhance T cell proliferation and differentiation appears to be conditioned by a high inter-individual variability (Fig. 1a, c), reflecting the known TLR polymorphisms or age-associated defects in human TLR function [19-22]. In spite of these variations, however, the adjuvant activity of each TLR agonist depends on the type of APC inducing T cell activation.

IL- 6 and TNF- $\alpha$ are cell-restricted molecular signatures of TLR2/4 stimulation

We next asked whether Mo and DC similarly respond to the same TLR agonists. To this aim, we stimulated CD14 cells, and Mo undergoing DC differentiation in vitro (according to ref. [23]) with $\mathrm{P}_{3} \mathrm{CSK}_{4}$, Lipid A and Poly I:C and measured the secretion of IL- 6 and TNF- $\alpha$ cytokines, known to be induced by TLR engagement in human APC $[11,24]$. Treatment with the $\mathrm{CSK}_{4}$ control peptide did not stimulate cytokines release at any time from day 0 to day 5 of culture (Fig. 2). Similar results were obtained upon stimulation of CD14 ${ }^{+}$cells with Poly I:C (Fig. 2, day 0). Monocyte, however, produced high amounts of IL-6 in response to TLR2 and TLR4 agonists, with poor detection of TNF- $\alpha$ (Fig. 2 day 0). Mo differentiated by culture with GM-CSF/ IL-4 and then stimulated with TLR 2 and TLR4 agonists, produced sevenfold less IL- 6 and threefolds more TNF- $\alpha$ (Fig. 2 days 1 and 3). At day 5 of differentiation these cells responded to $\mathrm{P}_{3} \mathrm{CSK}_{4}$ and Lipid A by secreting even higher amount of TNF- $\alpha$, but poorly detectable IL-6 (Fig. 2 day 5). At this time point the culture contained fully differentiated DC, as indicated by their increased cell size, lack of CD14 and de novo expression of CD1a, as compared to Mo cultures assessed from day 0 to day 3 of differentiation (Fig. 2c). The cell-restricted cytokine profile was also observed by determining the kinetic of IL- 6 and TNF- $\alpha$ release from TLR-stimulated Mo and terminally differentiated DC from $30 \mathrm{~min}$ to $22 \mathrm{~h}$ upon stimulation (Fig. 3). Notably, TLR3 engagement by Poly I:C resulted in poor cytokine secretion in either cell type (Figs. 2,3).

These results indicate that human Mo and DC respond distinctly to TLR2/TLR4 stimulation in vitro, and define IL- 6 and TNF- $\alpha$ as cell-restricted molecular signatures of activation, by these two cell types, respectively.

\section{CXCL10 signature in response to TLR3 triggering}

We then asked whether diverse patterns of TLR expression in Mo and DC could explain the time-dependent switch in cytokines secretion observed above. By using specific monoclonal antibodies to monitor TLR2 expression, we found a higher cell surface expression of the specific protein on freshly purified $\mathrm{CD} 14^{+}$cells as compared to DC (Fig. 4a). Consistent with this, culture of Mo in medium promoting DC differentiation resulted in a time-dependent reduction of TLR2 specific mRNA (Fig. 4b). DC differentiation in vitro 

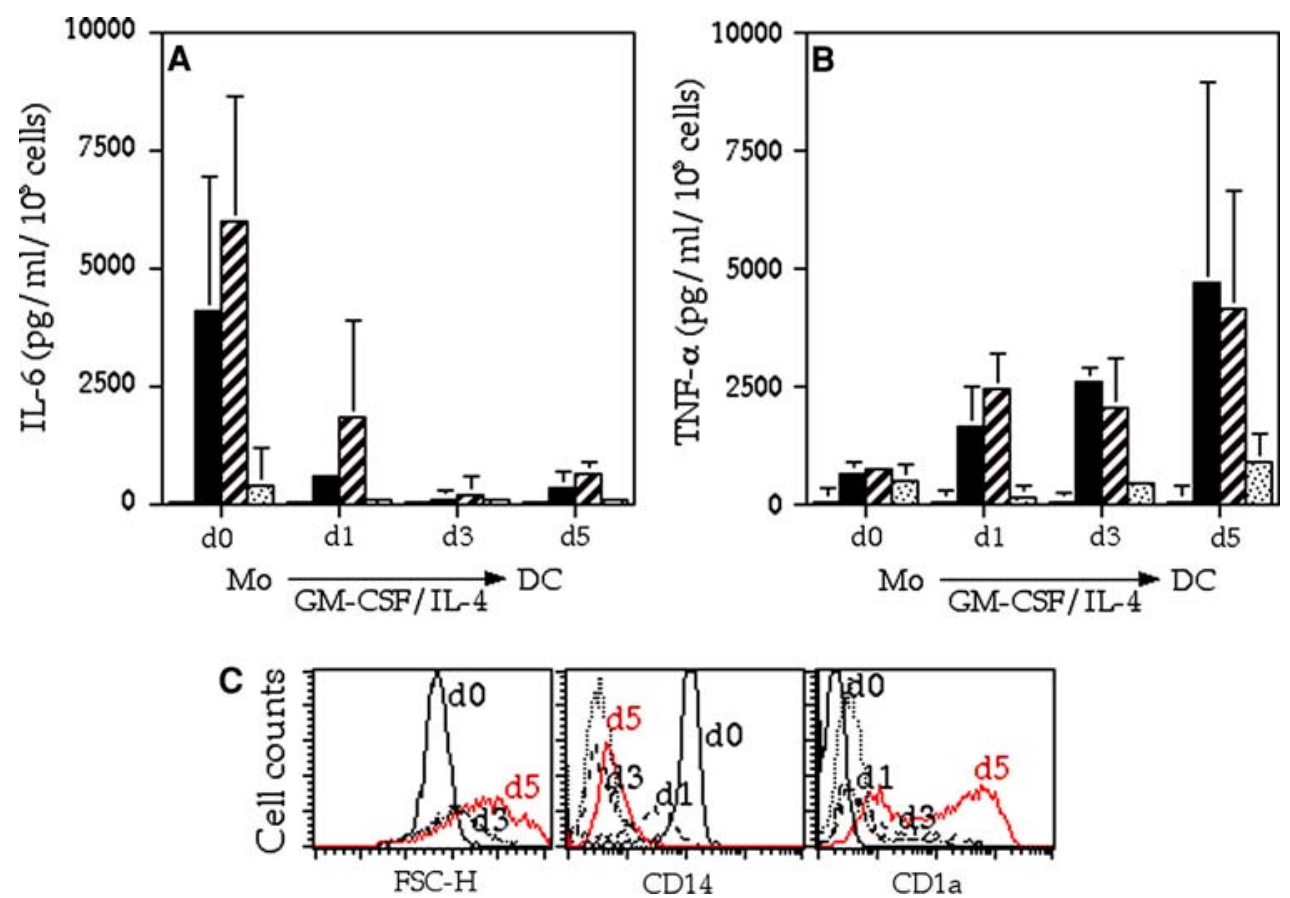

Fig. 2 Mo and DC respond distinctly to TLR2, TLR4 and TLR3 agonists in vitro. Freshly purified $\mathrm{CD} 14^{+}$cells (d0) and Mo undergoing DC differentiation (d1-d5) upon culture in GM-CSF/IL-4 conditioned medium, were stimulated with $\mathrm{CSK}_{4}$ (white bars), $\mathrm{P}_{3} \mathrm{CSK}_{4}$ (black bars), Lipid A (hatched bars) and Poly I:C (dotted bars). Secretion of IL-6 (a) and TNF- $\alpha$ (b) in culture supernatants was assessed by specific
ELISA assays. Data are given as mean results \pm SD obtained in four donors independently tested and are expressed in $\mathrm{pg} / \mathrm{ml} / 10^{5}$ cells. c Time-dependent variation in cell size (FSC-H) and surface expression of CD14 and CD1a during Mo culture in GM-CSF/IL-4. Plots show profiles obtained with cells at days $0,1,3$ and 5 of differentiation by FACS analysis. Results are representative of four experiments was also characterized by a fourfold reduction of TLR4 gene transcription and a decreased transcription of TLR1 specific gene (Fig. 4b). In sharp contrast, mRNA encoding TLR3, was not detected in freshly isolated Mo, and first detected after 3 days of culture in medium containing GM-CSF/IL-4, rising to a fourfolds higher magnitude at day 5 (Fig. 4b).

We then studied the biological consequences of the differential TLR expressions, by monitoring the timedependent secretion of CCL2 and CXCL10 chemokines which are known to depend, at least in part, on TRIF signaling downstream from TLR4 and TLR3, particularly in DC $[25,26]$. CCL2 was detected in culture supernatants of Mo undergoing DC differentiation in vitro stimulated with $\mathrm{P}_{3} \mathrm{CSK}_{4}$ and Lipid $\mathrm{A}$, at any time point tested, although more consistently in the presence of the TLR2 agonists (Fig. 4d). Strikingly, detection of both CCL2 and CXCL10 upon cell stimulation with Poly I:C was detected only on days 3 and 5 of culture (Fig. 4c, d). Remarkably, CXCL10 release uniquely depended on TLR3 signaling, in sharp contrast to CCL2, which was released upon stimulation with all TLR agonists.

Altogether, our study confirms and extends previous findings [11, 27], suggesting that quantitative and qualitative differences in TLR expression on Mo and DC results in a cell-restricted activation program in response to the cognate ligand. In addition, CXCL10 represents a specific signature of TLR3 signaling, at least in our settings.

Cell-restricted and agonist-specific signatures in response to TLR2, TLR4 and TLR3 activation

To obtain a broader pattern of molecular profiles induced by TLR engagement in functionally different APC, we have extended our analysis to the expression of 21 genes, encoding soluble factors involved in inflammation (TNF- $\alpha$, IFN$\beta 1$, IL-1 $\beta$, IL-18, CCL3, CCL20), induction of adaptive immune responses (IFN- $\gamma$, IL-4, IL-7, IL-12p40, IL-12p35, IL-15, IL-23p19, IL-27p28, EBI3, CXCL10, CX3CL1, CCL5, CCL22) and immune regulation (TGF- $\beta 1$, IL-10). Quantitative gene expression analysis was assessed in freshly purified $\mathrm{CD}_{14}{ }^{+}$Mo and DC stimulated with $\mathrm{P}_{3} \mathrm{CSK}_{4}$, Lipid A or Poly I:C and relative gene expression values were calculated as compared to control cultures stimulated in the presence of PBS. Results obtained with three different donors are reported in Table 1. Because of the inter-individual variability, only gene expression profiles observed at similar magnitude in all donors tested are presented and discussed here below. 
Fig. 3 Time-course analysis of TLR3 and TLR4 triggering on $\mathrm{CD} 14^{+} \mathrm{Mo}$ and $\mathrm{DC}$ in vitro. Freshly purified Mo $(\mathbf{a}, \mathbf{b})$ or Mo-derived DC $(\mathbf{c}, \mathbf{d})$ were stimulated, at $2 \times 10^{5}$ cells $/ \mathrm{ml}$, with $\mathrm{CSK}_{4}$ (open circle), $\mathrm{P}_{3} \mathrm{CSK}_{4}$ (filled circle), Lipid A (filled square) and Poly I:C (open square and culture supernatants $\alpha(\mathbf{b}, \mathbf{d})$ secretion at different time points between 0.5 and $22 \mathrm{~h}$. Representative results obtained in two out of three donors tested are shown cytokines release upon TLR2, assessed for IL-6 (a, c) and TNF-
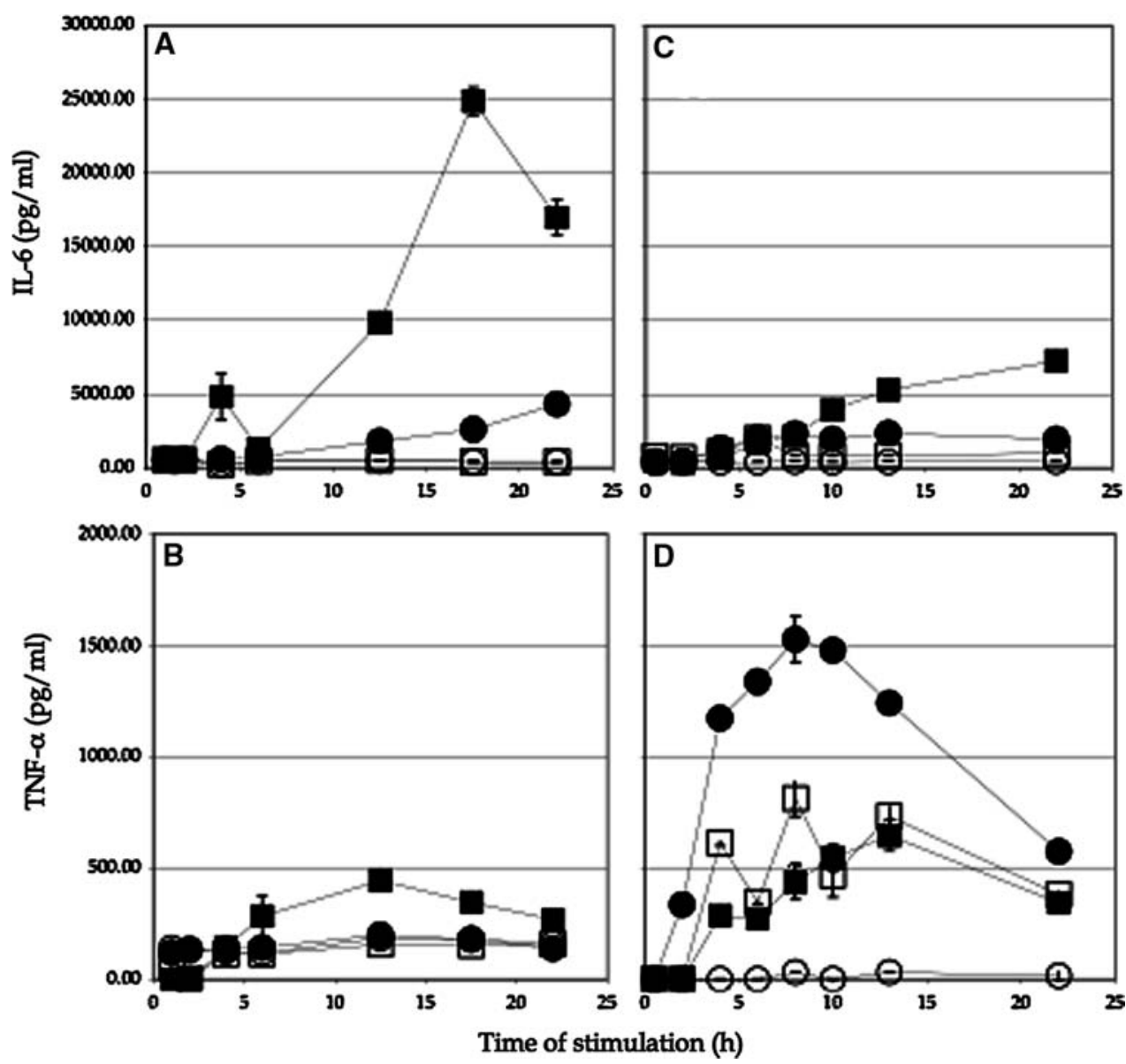

Stimulation with $\mathrm{P}_{3} \mathrm{CSK}_{4}$ resulted in the up-regulation of 9/21 genes in Mo and 10/21 genes in DC. Transcription of TNF- $\alpha$ and IL-12p35 specific genes was significantly increased only in DC, in contrast to IL-10 mRNA which was found more significantly increased in CD14 ${ }^{+}$Mo [24]. Moreover, the expression of eight genes, i.e. IL-1 $\beta$, IL-7, IL-12p40, IL-23, IL-27p28, EBI3, CCL3, CCL5 and CCL20 was increased in both cell types. In none of the two cell types, $\mathrm{P}_{3} \mathrm{CSK}_{4}$ induced up-regulation of IL-4, TGF- $\beta 1$ and CCL22 specific mRNA (Table 1, left panels).

Upon stimulation with Lipid A, 6/21 genes were significantly up-regulated in $\mathrm{CD}_{14}{ }^{+} \mathrm{Mo}$, and only $5 / 21$ in DC. Increased transcription of TNF- $\alpha$ was measured only in DC, while increased IL-1 $\beta$, IL-23p19 and CCL20 gene expression was detected in both cell types. Similarly to the TLR2 agonist just described, Lipid A stimulation never resulted in increased transcription of IL-4, TGF- $\beta 1$ and CCL22 specific genes (Table 1, central panels).

Stimulation with Poly I:C induced the up-regulation of $10 / 21$ genes in DC (TNF- $\alpha$, IFN- $\beta 1$, IL- $1 \beta$, CCL3, IFN- $\gamma$, IL-12p35, IL-27p28, CXCL10, CCL5), but had no consistent effects on Mo gene expression. For a total of eight genes, including IL-4, IL-10, IL-18, IL-23p19, EBI3, CCL22, CX3CL1 and TGF- $\beta 1$ no increased expression was observed in DC (Table 1, right panels).
Three important findings derived from the gene profiles described above. First, TNF- $\alpha$ gene expression is increased in DC upon stimulation with all TLR agonists under investigation, although $\mathrm{TNF}-\alpha$ protein release does not represent a consistent signature of DC activation with Poly I:C (Fig. 2, ref. [12]). Second, the transcription of few genes is associated to specific TLR agonists. In particular, IL-23p19 specific mRNA, is up-regulated by both $\mathrm{P}_{3} \mathrm{CSK}_{4}$ and Lipid A, but not by Poly I:C. In contrast, CXCL10-specific gene is highly increased in DC only upon Poly $\mathrm{I}: \mathrm{C}$ stimulation, thus confirming our protein expression data (Fig. 3). Third, all TLR agonists under investigation are able to increase the expression of IL- $1 \beta$ gene, irrespective of the responding cell type. IL- $1 \beta$ protein release characterizes Mo activation
by Lipid A

At a first sight, the detection of IL- $1 \beta$ specific gene transcription in Mo and DC upon stimulation with any TLR agonist under investigation was puzzling. IL- $1 \beta$ is produced as a cytoplasmic precursor that needs to be first processed and then secreted to act as endogenous pyrogen in vivo [28]. Indeed, biologically active IL- $1 \beta$ is responsible for the endotoxin shock induced by exposure to LPS and 
Fig. 4 TLR3 is specifically expressed on DC and CXCL10 represents a cell-restricted signature of activation in response to Poly I:C. Freshly isolated CD $14^{+}$ Mo were cultured in the presence of GM-CSF/IL-4 and analyzed by FACS staining or qRTPCR at days (d) $0,1,3$ and 5. a TLR2 surface expression in freshly isolated Mo (d0) and terminally differentiated DC (d5). In each plot dotted lines represent the background staining with an isotype-matched control antibody. b Quantitative gene expression analysis of TLR1, TLR2, TLR3 and TLR4 specific mRNA; data are expressed as Relative Quantity (R. Q.); cells at day 5 of culture were taken as calibrator (R. Q. = 1). Timedependent induction of CCL2 and CXCL10 chemokines in response to $\mathrm{CSK}_{4}$ (white bars), $\mathrm{P}_{3} \mathrm{CSK}_{4}$ (black bars), Lipid A (hatched bars) and Poly I:C (dotted bars) in Mo undergoing DC differentiation in vitro is shown in $\mathbf{c}$ and $\mathbf{d}$, respectively. Data are represented as described in Fig. 2
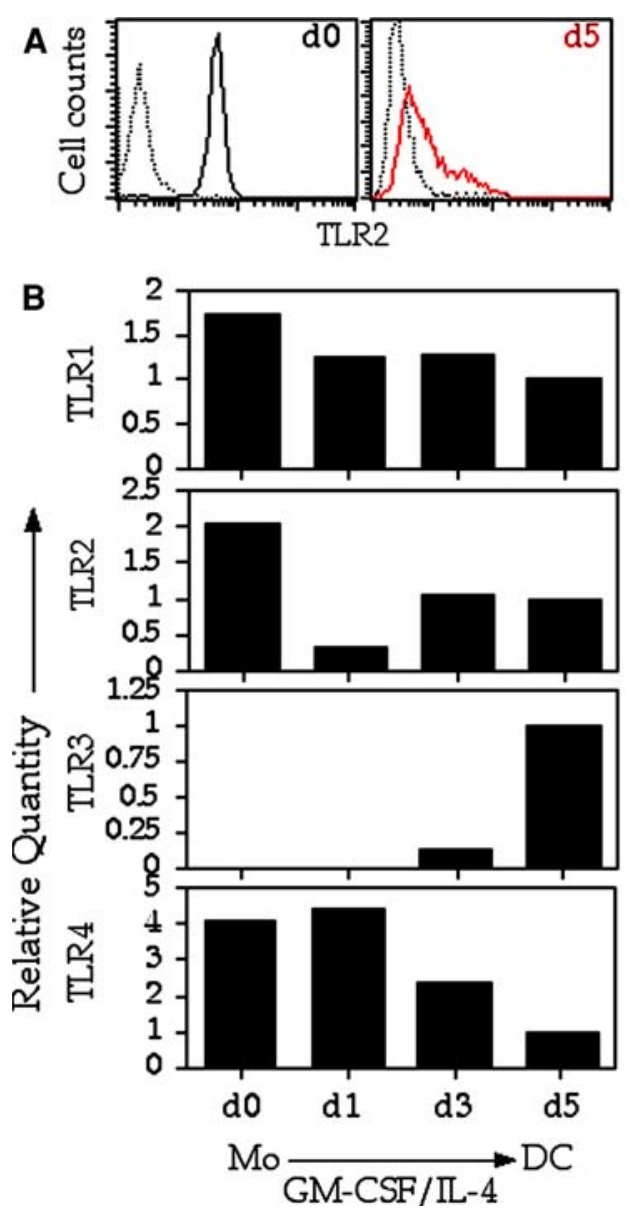
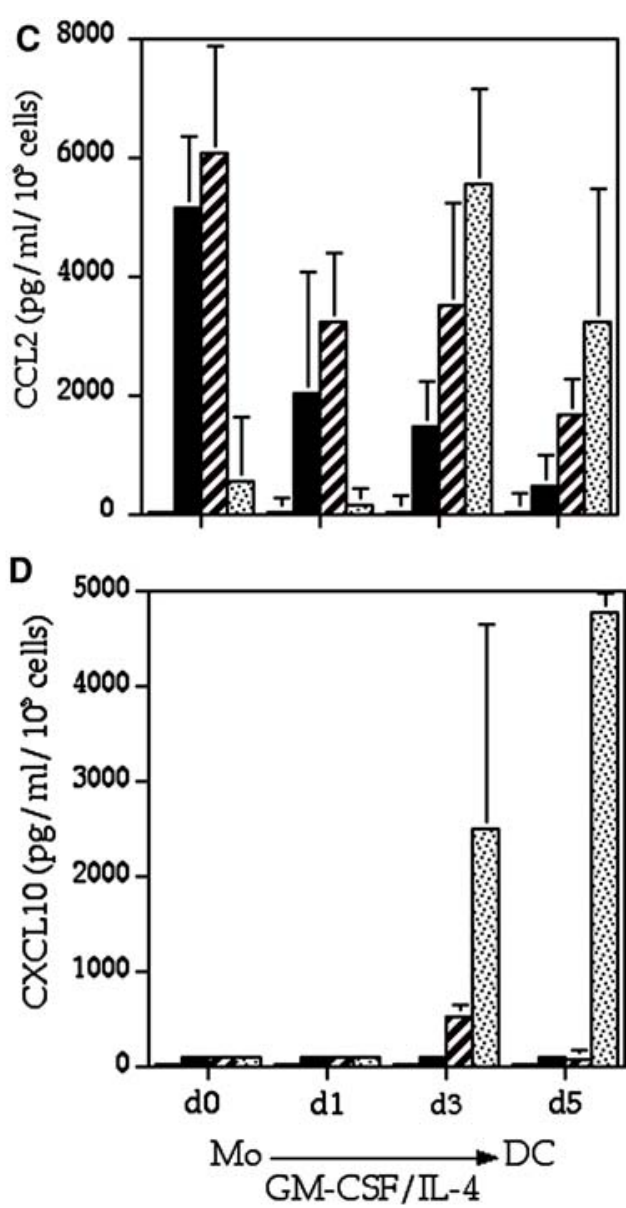

Lipid A in vivo [29, 30]. In contrast, endotoxin-free preparations of $\mathrm{P}_{3} \mathrm{CSK}_{4}$ and Poly I:C are known to act as safe adjuvants when injected into animals $[31,32]$.

In order to understand the apparent discrepancy between the capacity of $\mathrm{P}_{3} \mathrm{CSK}_{4}$ and Poly I:C to induce IL- $1 \beta$ gene transcription, while lacking in vivo toxicity, we asked whether signaling through TLR2, 4 and 3 in Mo undergoing DC differentiation in vitro results in IL- $1 \beta$ protein secretion. To this aim we used the same cell cultures setting described in Fig. 2 and measured release of IL-1 $\beta$ in cell culture supernatants by specific ELISA. Remarkably, up to $135 \mathrm{pg} / \mathrm{ml}$ of IL- $1 \beta$ was only detected in culture supernatants of Mo stimulated with Lipid A, while any other condition of stimulation, irrespective of the cell differentiation stage, scored negative (Fig. 5a). We also found that the production of IL- $1 \beta$ by Mo in response to Lipid A was inversely correlated to the concentration of this specific TLR4 agonist, with maximum release of IL- $1 \beta$ at doses of Lipid A below $10 \mathrm{ng} / \mathrm{ml}$.

Altogether, these results indicate that IL- $1 \beta$ production characterizes the activation of primary human Mo by the TLR4 agonist Lipid A and defines this cytokine as a molecular signature of pyrogenicity in vitro.
Applicability of molecular signatures for compounds selection

The definition of cell-restricted molecular signatures predicting adjuvanticity and safety of immune stimulatory factors can facilitate the large-scale screening of chemical libraries for the selection of putative adjuvants suitable for human vaccines.

In order to determine the applicability of our findings for compounds selection, we first determined the correlation between TNF- $\alpha$ release by stimulated DC and expansion of IFN $\gamma^{+} / \mathrm{CD}^{+} \mathrm{T}$ cells in MLR cultures conditioned by various synthetic and natural agonists of TLR2, including analogs of the $\mathrm{P}_{3} \mathrm{CSK}_{4}$ lipopeptide and recombinant Lip-OspA lipoprotein from Borrelia burgdorferi. Results presented in Fig. 6a, show a significative positive correlation between those two parameters $\left(R^{2}=0.9023 ; P=0.0093\right)$. Thus, we assume that the amount of TNF- $\alpha$ produced in vitro is a measure of the adjuvant activity of each single compound tested.

Next, we studied the in vitro immune stimulatory effects of a larger chemical library, including all TLR-2 agonists tested above as well as pathogens molecules, i.e. CT from 
Table 1 Expression of cytokines and chemokines specific genes in $\mathrm{CD}_{1}{ }^{+}$cells and monocyte-derived DC upon stimulation with P3CSK4, LipidA and Poly I:C

\begin{tabular}{|c|c|c|c|c|c|c|c|c|c|c|c|c|c|c|c|c|c|c|}
\hline & \multicolumn{6}{|l|}{$\mathrm{P} 3 \mathrm{CSK} 4$} & \multicolumn{6}{|l|}{ Lipid A } & \multicolumn{6}{|c|}{ Poly I:C } \\
\hline & \multicolumn{2}{|l|}{ Donor 1} & \multicolumn{2}{|c|}{ Donor 2} & \multicolumn{2}{|c|}{ Donor 3} & \multicolumn{2}{|l|}{ Donor 1} & \multicolumn{2}{|c|}{ Donor 2} & \multicolumn{2}{|c|}{ Donor 3} & \multicolumn{2}{|c|}{ Donor 1} & \multicolumn{2}{|c|}{ Donor 2} & \multicolumn{2}{|c|}{ Donor 3} \\
\hline & & $\mathrm{DC}$ & Mo & $\mathrm{DC}$ & 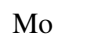 & $\mathrm{DC}$ & Mo & DC & Mo & DC & Mo & $\mathrm{DC}$ & Mo & DC & Mo & $\mathrm{DC}$ & Mo & DC \\
\hline \multicolumn{19}{|c|}{ Inflammation } \\
\hline TNF- $\alpha$ & 3.2 & 37.6 & 1.0 & 22.4 & 4.9 & 17.7 & 1.0 & 4.1 & 1.0 & 55.7 & 1.6 & 3.8 & 1.0 & 7.5 & 1.0 & 28.6 & 1.1 & 7.9 \\
\hline IFN- $\beta 1$ & 3.1 & 6.0 & 1.9 & 5.3 & 1.0 & 1.0 & 2.7 & 5.8 & 1.4 & 918.6 & 1.3 & 1.6 & 2.0 & 46.0 & 1.0 & 24.8 & 1.0 & 9.5 \\
\hline IL- $1 \beta$ & 28.2 & 213.0 & 88.7 & 73.3 & 11.9 & 139.6 & 9.0 & 17.9 & 27.6 & 376.0 & 8.4 & 20.1 & 1.8 & 4.8 & 3.5 & 18.0 & 1.5 & 8.5 \\
\hline IL-18 & 1.2 & 2.5 & 4.2 & 1.9 & 1.7 & 2.0 & 1.0 & 1.2 & 2.7 & 3.2 & 1.0 & 1.2 & 1.0 & 1.0 & 1.4 & 1.4 & 1.0 & 1.0 \\
\hline CCL3 & 11.7 & 18.5 & 13.6 & 20.9 & 6.5 & 8.7 & 4.5 & 4.4 & 8.2 & 27.9 & 5.8 & 2.8 & 1.4 & 6.6 & 1.9 & 21.6 & 1.1 & 6.0 \\
\hline CCL20 & 101.9 & 277.9 & 209.9 & 84.6 & 19.3 & 39.5 & $\mathbf{1 7 . 8}$ & 28.6 & 45.9 & 118.6 & 12.5 & 4.5 & 2.0 & 4.8 & 4.9 & 15.6 & 1.5 & 1.6 \\
\hline \multicolumn{19}{|c|}{ Adaptive immunity } \\
\hline IFN- $\gamma$ & 1.0 & 1.0 & 14.6 & 1.0 & 1.0 & 1.0 & 843.1 & 1.0 & 53.9 & 10.8 & 1.0 & 71.7 & 1.0 & 653.2 & 16.0 & 60.4 & 1.0 & 351.4 \\
\hline IL-4 & 1.0 & 1.0 & 1.0 & 1.0 & 1.0 & 1.0 & 1.0 & 1.0 & 1.0 & 1.0 & 1.0 & 1.0 & 1.0 & 1.0 & 1.0 & 1.0 & 1.0 & 1.0 \\
\hline IL-7 & 12.6 & 12.5 & 12.9 & 10.9 & 8.1 & 2.3 & 3.3 & 4.9 & 10.7 & 9.9 & 9.4 & 1.8 & 1.0 & 6.5 & 1.0 & 4.1 & 1.0 & 2.5 \\
\hline IL-12p40 & 55.7 & 149.5 & 130.9 & 134.8 & 50.7 & 36.2 & 14.4 & 10.3 & 156.3 & 267.5 & 28.5 & 2.7 & 1.0 & 6.0 & 1.0 & 45.8 & 1.4 & 2.4 \\
\hline IL-12p35 & 1.5 & 7,582 & 1.0 & 158.3 & 5.8 & 11.1 & 2.4 & 311.7 & 3.3 & 258 & 14.2 & 1.2 & 1.0 & 2,452 & 1.0 & 116.0 & 1.0 & 4.6 \\
\hline IL-15 & $3,182.0$ & 12.6 & 1.0 & 2.8 & 5.7 & 2.5 & $1,502.0$ & 14.1 & 1.0 & 1.3 & 31.0 & 7.1 & 519.0 & 20.0 & 1.0 & 4.2 & 1.0 & 14.4 \\
\hline IL-23p19 & 166.1 & 392.5 & 44.5 & 228.0 & 343.3 & 174.0 & 25.2 & 39.9 & 32.7 & 12.2 & 83.4 & 534.9 & 2.5 & 1.0 & 2.0 & 1.0 & 6.6 & 1.8 \\
\hline IL-27p28 & 5.4 & 1,906 & 4.3 & 753.0 & 6.2 & 52.9 & 1.8 & 661.6 & 26.3 & 45.4 & 122.2 & \#\#\#\#\# & 1.1 & \#\#\#\#\# & 1.0 & $7,065.9$ & 2.3 & \#\#\#\#\# \\
\hline EBI3 & 43.5 & 9.1 & 7.6 & 7.3 & 13.8 & 13.1 & 5.2 & 1.9 & 9.0 & 1.0 & 8.9 & 33.2 & 1.3 & 1.0 & 1.0 & 1.8 & 1.6 & 2.8 \\
\hline CXCL10 & 1.0 & 4.9 & 1.0 & 1.0 & 1.0 & 28.8 & 1.0 & 1.0 & 56.9 & 1.0 & 7.0 & 16.5 & 1.0 & \#\#\#\#\# & 1.2 & 3,821 & 1.0 & \#\#\#\#\# \\
\hline CX3CL1 & 1.0 & 4.4 & 1.0 & 3.5 & 1.0 & 1.6 & 1.0 & 3.4 & 1.0 & 2.6 & 1.0 & 1.3 & 1.0 & 1.1 & 1.0 & 1.1 & 1.0 & 1.0 \\
\hline CCL5 & 5.2 & 7.9 & 5.8 & 21.3 & 4.0 & 3.4 & 3.9 & 2.9 & 20.1 & 141.6 & 9.1 & 1.9 & 1.0 & 7.0 & 1.6 & 100.3 & 1.2 & 5.0 \\
\hline CCL22 & 1.0 & 1.2 & 1.0 & 1.8 & 1.0 & 1.3 & 1.0 & 1.0 & 1.0 & 1.1 & 1.0 & 1.0 & 1.0 & 1.0 & 1.0 & 1.0 & 1.0 & 1.0 \\
\hline \multicolumn{19}{|c|}{ Immuneregulation } \\
\hline TGF- $\beta 1$ & 1.0 & 1.0 & 1.0 & 1.0 & 1.0 & 1.0 & 1.0 & 1.0 & 1.0 & 1.0 & 1.0 & 1.0 & 1.0 & 1.1 & 1.0 & 1.0 & 1.0 & 1.0 \\
\hline IL-10 & 14.1 & 3.7 & 14.5 & 1.0 & 9.3 & 1.5 & 2.3 & 1.0 & 5.6 & 1.0 & 8.4 & 1.0 & 1.0 & 1.3 & 1.0 & 1.0 & 1.0 & 2.8 \\
\hline
\end{tabular}

Data are expressed in Relative Quantity (R.Q.) as compared to cell cultures stimulated in the presence of PBS (R.Q. = 1.0). A threshold of 1.0 was assigned to any gene with a R.Q. $<1.0$. Values $\geq 3.0$ are considered indicative of enhanced gene expression and are shown in bold. Results obtained from three independent donors are shown

Vibrio cholerae, PT from Bordetella pertussis, SMEA and IPSE from Schistosoma mansoni, that do not depend on TLR for cell activation. In our assay $\mathrm{CSK}_{4}, \mathrm{P}_{3} \mathrm{CSK}_{4}$, Lipid $\mathrm{A}$ and Poly I:C were used as internal standards with the aim of selecting potential safe adjuvants from the chemical library. We set a cutoff for positive selection at $123 \mathrm{pg} / \mathrm{ml}$ for TNF- $\alpha$ and $11 \%$ for Th1 expansion, corresponding to the mean value obtained upon stimulation with Poly I:C, which scored as weakest adjuvant throughout our study (Fig. 6b left and central panels). A cutoff for negative selection was set above $105 \mathrm{pg} / \mathrm{ml}$ of IL- $1 \beta$, corresponding to the mean value obtained upon stimulation with Lipid A (Fig. $6 \mathrm{~b}$ right panel). Six out of 14 compounds tested were selected according to their capacity to induce TNF- $\alpha$ above the cutoff, i.e. $\mathrm{PCPCSK}_{4}, \mathrm{P}_{2} \mathrm{CSK}_{4}, \mathrm{Myr}_{2} \mathrm{CSK}_{4}, \mathrm{Ole}_{2} \mathrm{CSK}_{4}$, MALP2 and Lip-OspA. When tested for the capacity to induce Th1 responses, $\mathrm{P}_{2} \mathrm{CSK}_{4}, \mathrm{Ole}_{2} \mathrm{CSK}_{4}$ and Lip-OspA scored above the cutoff of $11 \%$. Among these three compounds, Lip-OspA also induced IL- $1 \beta$ secretion above the cutoff of $105 \mathrm{pg} / \mathrm{ml}$, thus leaving $\mathrm{P}_{2} \mathrm{CSK}_{4}$ and $\mathrm{Ole}_{2} \mathrm{CSK}_{4}$ as the unique selected molecules. Indeed, these compounds are known to act as safe adjuvants in animal models [31], thus supporting the applicability of our method for the selection of potential vaccine adjuvants prior to in vivo studies.

\section{Discussion}

This study provides the rational for the screening and subsequent development of adjuvants suitable for use in human vaccines based on responses observed on human $\mathrm{T}$ cells and APC. In contrast, most current methods for adjuvant selection are based on in vivo studies in a variety of animal models not necessarily representative of human reactivity. 


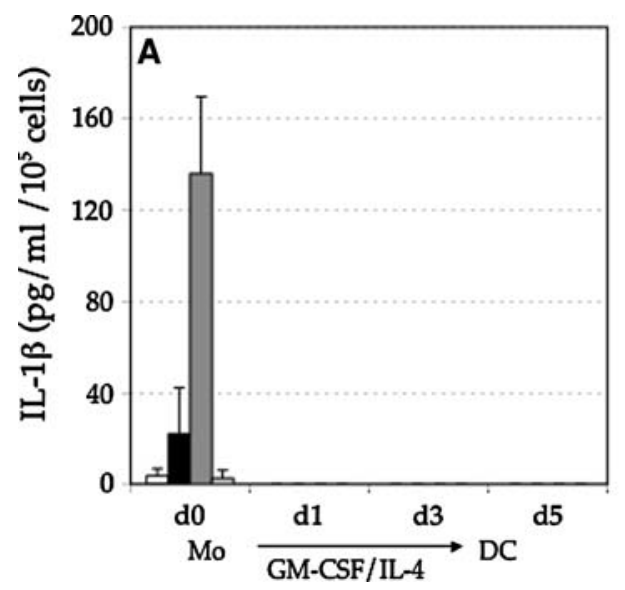

Fig. 5 IL $1 \beta$ is a molecular marker of pyrogenicity. Freshly purified $\mathrm{CD} 14^{+}$cells (d0) and Mo undergoing DC differentiation (d1-d5) upon culture in GM-CSF/IL-4 conditioned medium, were stimulated with $\mathrm{CSK}_{4}$ (white bars), $\mathrm{P}_{3} \mathrm{CSK}_{4}$ (black bars), Lipid A (gray bars) and Poly I:C (dotted bars). Amounts of IL-1 $\beta$ a in culture supernatants, as assessed by specific ELISA assays are expressed in $\mathrm{pg} / \mathrm{ml} / 10^{5}$ cells. Data

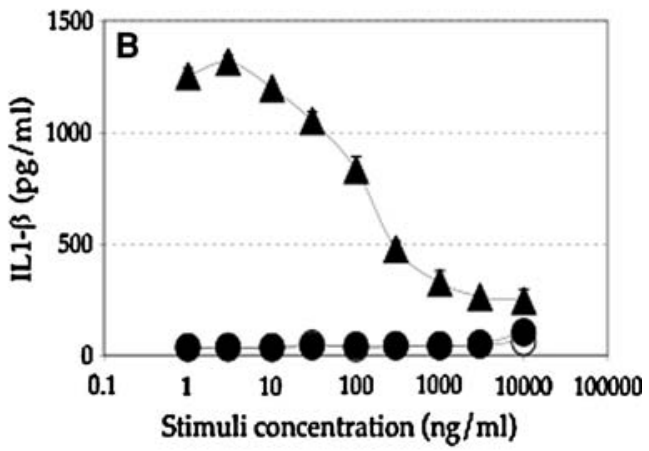

are representative of three independent experiments. b Dose-dependent induction of IL- $1 \beta$ in Mo stimulated with $\mathrm{CSK}_{4}$ (open circle), $\mathrm{P}_{3} \mathrm{CSK}_{4}$ (filled circle) and Lipid A (filled triangle) at $10^{4}-1 \mathrm{ng} / \mathrm{ml}$ in threefolds serial dilutions. Experimental data obtained from one out of three donors independently tested are expressed in $\mathrm{pg} / \mathrm{ml}$ and shown as mean results of triplicate wells
Fig. 6 Prediction of adjuvant activity and safety of synthetic and natural compounds. a Correlation between amount of TNF- $\alpha$ released by $\mathrm{DC}$ and induction of Th1 responses in vitro upon stimulation with different natural and synthetic TLR-2 agonists. b Selection of putative safe adjuvants among a chemical library of 14 compounds including TLR-dependent and -independent stimuli, according to the capacity of each molecule to induce TNF- $\alpha$ secretion from activated DC (left panel), expansion of IFN $-\gamma^{+} / \mathrm{CD}^{+} \mathrm{T}$ lymphocytes in MLR cultures (central panel) and IL- $1 \beta$ from CD $14^{+}$Mo in vitro (right panel). Cutoff for positive and negative selection are indicated by red and black arrows, respectively. Positively selected compounds are labeled in red

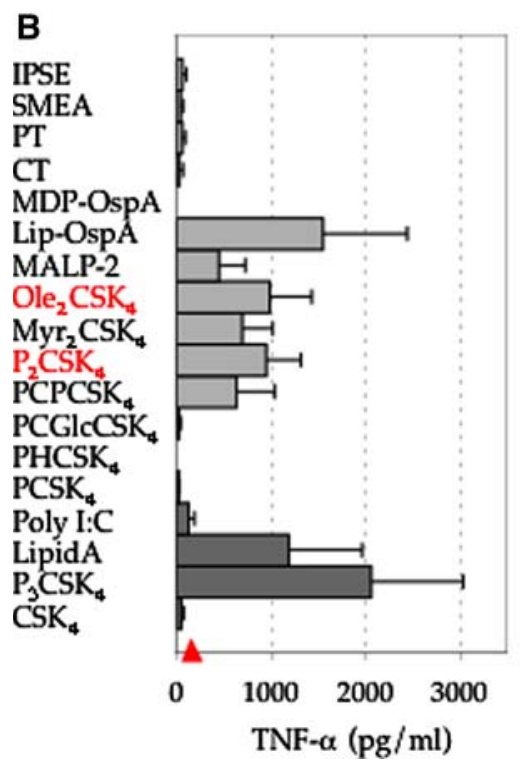

A

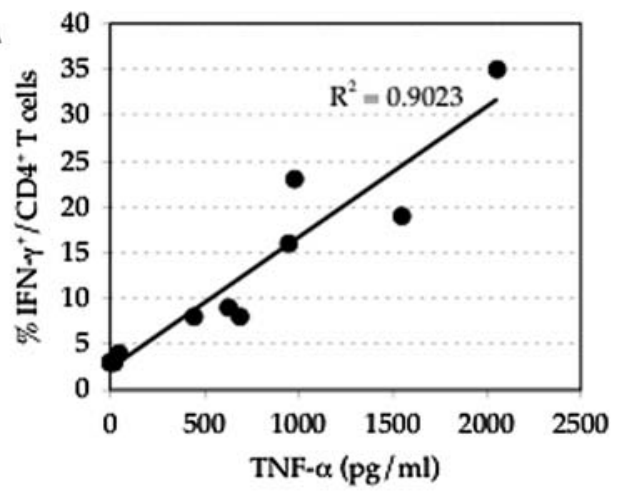


potential to act as safe adjuvants in vivo. Second, TNF- $\alpha$ and CXCL10 represent molecular signatures of adjuvanticity. Third, IL- $1 \beta$ represents an in vitro marker of pyrogenicity and this signature is restricted to primary Mo.

A comparaison of human Mo and DC as examples of functionally different APC, show that DC but not Mo do effectively prime $\mathrm{CD} 4^{+} \mathrm{T}$ cells in the presence of TLR agonists in vitro. The molecular signatures of each of these two APC subsets to TLR signaling were then analyzed in terms of induction of relevant cytokines and chemokines. Thus, based of the knowledge that DC are professional APC endowed with full $\mathrm{T}$ cell priming capacity, we define TNF$\alpha$ and CXCL10 as molecular signatures of the adjuvant activity of TLR2/4 and TLR3 agonists, respectively.

Molecular patters of adjvanticity do not necessarily correlate with the safety of an immune enhancer. Indeed, the risk of inducing endotoxic shock in vivo represents a limitation for the transfer of adjuvants in practical medicine, even when the compounds tested lack toxicity in animal models. Although TNF- $\alpha$ and IL- 6 can act as pyrogenic molecules when injected in animals, the most potent fever-inducing factor in vivo is IL- $1 \beta$, being active at sub-nanomolar doses in humans [28]. We found that Lipid A stimulation of Mo, but not DC, resulted in IL- $1 \beta$ release at doses which could be pyrogenic in vivo. In contrast, stimulation of both cell types with the synthetic TLR2 agonist $\mathrm{P}_{3} \mathrm{CSK}_{4}$ and the TLR3 ligand Poly I:C resulted in induction of proIL- $1 \beta$-specific gene transcription, in the absence of bioactive IL- $1 \beta$ release. These results are consistent with animal models documenting the lack of toxicity of $\mathrm{P}_{3} \mathrm{CSK}_{4}$ and Poly I:C, as compared to the lethal effect of Lipid A [30-32]. Our results also confirm previous finding on the capacity of Lipid A to stimulate IL- $1 \beta$ induction, and, importantly, reveal that primary human Mo are sensitive to a lower concentration range of pyrogens as compared to murine Mo or immortalized macrophage cell lines in vitro [33]. The latter stresses the importance of studying the relevant cellular model, in this case, human primary lymphocytes.

Based on the above findings, we used TNF- $\alpha$ and IL- $1 \beta$ signatures to predict adjuvant activity and pyrogenicity of a series of natural microbial molecules or synthetic analogs thereof. This simple method enabled us to select the only two compounds contained in the chemical library, known to act as safe adjuvants in vivo, thus demonstrating the applicability of our findings to identify potential adjuvants for humans. Although only few parameters of an immune response were modeled here, the method described presents a number of positive features. These include the simplicity and sensitivity of the biological responses assessed, the broad applicability of the assay and the fact that the system is based on human primary cells that require standard isolation procedures and in vitro culture. The high inter-individual variability observed represents an important concern,

\section{ADJUVANTS SELECTION IN VITRO}

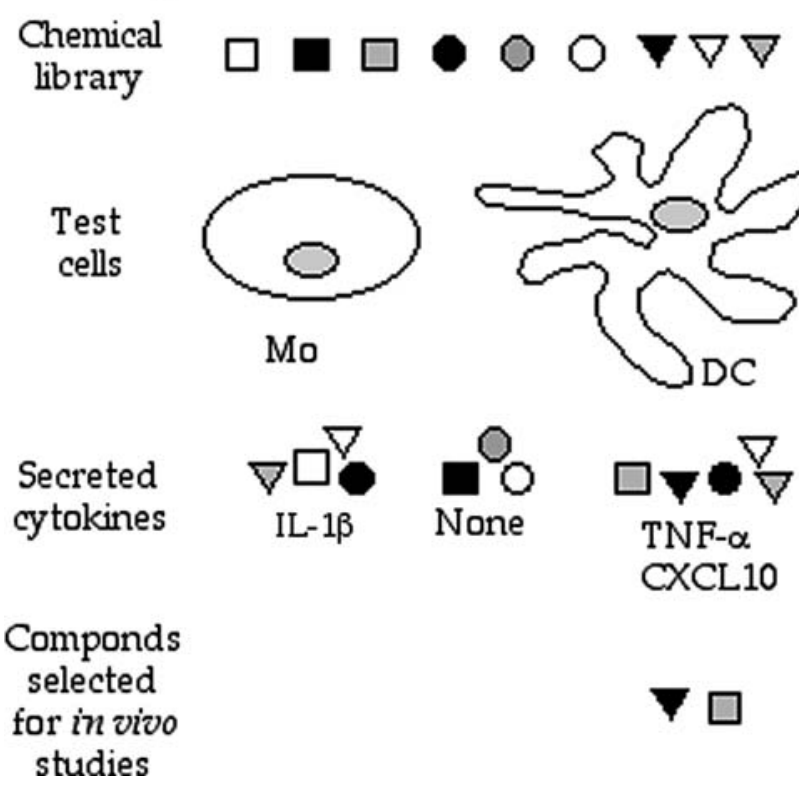

Fig. 7 Schematic representation of an applicable in vitro system for adjuvants selection. In the proposed methods chemical compounds of unknown adjuvant activity are tested for their capacity to induce IL- $1 \beta$ release from human Mos $(\mathrm{Mo})$ and TNF- $\alpha / \mathrm{CXCL} 10$ secretion by Moderived dendritic cells $(D C)$. Only chemicals positive for TNF- $\alpha$ / CXCL10 and negative for IL- $1 \beta$ are selected for in vivo studies

which requires the establishment of accurate value of reference for the selected parameters, standardized procedures to perform these assays but also age-matched blood donors [22]. For this implementation, there is need to identify adjuvants and pyrogens of reference, develop calibrated ELISA and MLR assays and select suitable blood donors.

In conclusion, the applicability of our method of screening to large-scale chemical libraries will facilitate the selection of candidate adjuvants prior in vivo testing, thus reducing the need of costly, demanding and potentially irrelevant animal studies. In a possible scenario, depicted in Fig. 7, pre-screening tests assessing the production of TNF$\alpha$ and/or CXCL10 by human DC, and IL- $1 \beta$ release by $\mathrm{CD} 14^{+}$Mo will narrow down the number of compounds that need to be assessed for enhanced immune protection and lack of toxicity in vivo.

Acknowledgments We thank Michael Parkhouse and Söhnke Voss for critical reading of the manuscript. This work was supported by the 3R Research Foundation Switzerland (grant No. 92/04 to EP).

Competing interests No financial or non-financial interests.

\section{References}

1. Iwasaki A, Medzhitov R (2004) Toll-like receptor control of the adaptive immune responses. Nat Immunol 5:987-995 
2. Takeda K, Kaisho T, Akira S (2003) Toll-like receptors. Annu Rev Immunol 21:335-376

3. Alexopoulou L, Thomas V, Schnare M, Lobet Y, Anguita J, Schoen RT, Medzhitov R, Fikrig E, Flavell RA (2002) Hyporesponsiveness to vaccination with Borrelia burgdorferi OspA in humans and in TLR1- and TLR2-deficient mice. Nat Med 8:878884

4. Alexopoulou L, Holt AC, Medzhitov R, Flavell RA (2001) Recognition of double-stranded RNA and activation of NF-kappaB by Toll-like receptor 3. Nature 413:732-738

5. Poltorak A, Ricciardi-Castagnoli P, Citterio S, Beutler B (2000) Physical contact between lipopolysaccharide and toll-like receptor 4 revealed by genetic complementation. Proc Natl Acad Sci USA 97:2163-2167

6. Sporri R, Reis e Sousa C (2005) Inflammatory mediators are insufficient for full dendritic cell activation and promote expansion of CD4+ T cell populations lacking helper function. Nat Immunol 6:163-170

7. Padovan E, Landmann RM, De Libero G (2007) How pattern recognition receptor triggering influences $\mathrm{T}$ cell responses: a new look into the system. Trends Immunol 28:308-314

8. Kanzler H, Barrat FJ, Hessel EM, Coffman RL (2007) Therapeutic targeting of innate immunity with Toll-like receptor agonists and antagonists. Nat Med 13:552-559

9. Pashine A, Valiante NM, Ulmer JB (2005) Targeting the innate immune response with improved vaccine adjuvants. Nat Med 11:S63-S68

10. Visintin A, Mazzoni A, Spitzer JH, Wyllie DH, Dower SK, Segal DM (2001) Regulation of Toll-like receptors in human monocytes and dendritic cells. J Immunol 166:249-255

11. Jarrossay D, Napolitani G, Colonna M, Sallusto F, Lanzavecchia A (2001) Specialization and complementarity in microbial molecule recognition by human myeloid and plasmacytoid dendritic cells. Eur J Immunol 31:3388-3393

12. Kadowaki N, Ho S, Antonenko S, Malefyt RW, Kastelein RA, Bazan F, Liu YJ (2001) Subsets of human dendritic cell precursors express different toll-like receptors and respond to different microbial antigens. J Exp Med 194:863-869

13. Trombetta ES, Mellman I (2005) Cell biology of antigen processing in vitro and in vivo. Annu Rev Immunol 23:975-1028

14. Freudenberg MA, Fomsgaard A, Mitov I, Galanos C (1989) ELISA for antibodies to lipid A, lipopolysaccharides and other hydrophobic antigens. Infection 17:322-328

15. Schramm G, Falcone FH, Gronow A, Haisch K, Mamat U, Doenhoff MJ, Oliveira G, Galle J, Dahinden CA, Haas H (2003) Molecular characterization of an interleukin-4-inducing factor from Schistosoma mansoni eggs. J Biol Chem 278:18384-18392

16. Reschner A, Moretta A, Landmann R, Heberer M, Spagnoli GC, Padovan E (2003) The ester-bonded palmitoyl side chains of Pam3CysSerLys4 lipopeptide account for its powerful adjuvanticity to HLA class I-restricted CD8+ T lymphocytes. Eur J Immunol 33:2044-2052

17. Ghielmetti M, Reschner A, Zwicker M, Padovan E (2005) Synthetic bacterial lipopeptide analogs: structural requirements for adjuvanticity. Immunobiology 210:211-215

18. Kapsenberg ML (2003) Dendritic-cell control of pathogen-driven T-cell polarization. Nat Rev Immunol 3:984-993
19. Lorenz E, Mira JP, Cornish KL, Arbour NC, Schwartz DA (2000) A novel polymorphism in the toll-like receptor 2 gene and its potential association with staphylococcal infection. Infect Immun 68:6398-6401

20. Lorenz E, Mira JP, Frees KL, Schwartz DA (2002) Relevance of mutations in the TLR4 receptor in patients with gram-negative septic shock. Arch Intern Med 162:1028-1032

21. Schroeder JT, Bieneman AP, Xiao H, Chichester KL, Vasagar K, Saini S, Liu MC (2005) TLR9- and FcepsilonRI-mediated responses oppose one another in plasmacytoid dendritic cells by down-regulating receptor expression. J Immunol 175:5724-5731

22. van Duin D, Mohanty S, Thomas V, Ginter S, Montgomery RR, Fikrig E, Allore HG, Medzhitov R, Shaw AC (2007) Age-associated defect in human TLR-1/2 function. J Immunol 178:970-975

23. Sallusto F, Lanzavecchia A (1994) Efficient presentation of soluble antigen by cultured human dendritic cells is maintained by granulocyte/macrophage colony-stimulating factor plus interleukin 4 and downregulated by tumor necrosis factor alpha. J Exp Med 179:1109-1118

24. Thoma-Uszynski S, Kiertscher SM, Ochoa MT, Bouis DA, Norgard MV, Miyake K, Godowski PJ, Roth MD, Modlin RL (2000) Activation of toll-like receptor 2 on human dendritic cells triggers induction of IL-12, but not IL-10. J Immunol 165:3804-3810

25. Yamamoto M, Sato S, Hemmi H, Hoshino K, Kaisho T, Sanjo H, Takeuchi O, Sugiyama M, Okabe M, Takeda K, Akira S (2003) Role of adaptor TRIF in the MyD88-independent toll-like receptor signaling pathway. Science 301:640-643

26. Weighardt H, Jusek G, Mages J, Lang R, Hoebe K, Beutler B, Holzmann B (2004) Identification of a TLR4- and TRIF-dependent activation program of dendritic cells. Eur J Immunol 34:558564

27. Matsumoto M, Funami K, Tanabe M, Oshiumi H, Shingai M, Seto Y, Yamamoto A, Seya T (2003) Subcellular localization of Tolllike receptor 3 in human dendritic cells. J Immunol 171:31543162

28. Dinarello CA (2004) Infection, fever, and exogenous and endogenous pyrogens: some concepts have changed. J Endotoxin Res 10:201-222

29. Cunha FQ, Assreuy J, Moss DW, Rees D, Leal LM, Moncada S, Carrier M, O'Donnell CA, Liew FY (1994) Differential induction of nitric oxide synthase in various organs of the mouse during endotoxaemia: role of TNF-alpha and IL-1-beta. Immunology 81:211-215

30. Freudenberg MA, Galanos C (1990) Bacterial lipopolysaccharides: structure, metabolism and mechanisms of action. Int Rev Immunol 6:207-221

31. Bessler WG, Mittenbuhler K, Esche U, Huber M (2003) Lipopeptide adjuvants in combination treatment. Int Immunopharmacol 3:1217-1224

32. Heikenwalder M, Polymenidou M, Junt T, Sigurdson C, Wagner H, Akira S, Zinkernagel R, Aguzzi A (2004) Lymphoid follicle destruction and immunosuppression after repeated $\mathrm{CpG}$ oligodeoxynucleotide administration. Nat Med 10:187-192

33. Okemoto K, Kawasaki K, Hanada K, Miura M, Nishijima M (2006) A potent adjuvant monophosphoryl lipid A triggers various immune responses, but not secretion of IL-1beta or activation of caspase-1. J Immunol 176:1203-1208 